\title{
The reconceptualisation of knowledge base in the pre-service teacher education curriculum: Towards ELF pedagogy
}

\author{
Zulfa Sakhiyya*, Helena I.R. Agustien, and Hendi Pratama \\ English Department, Faculty of Languages and Arts, Universitas Negeri Semarang, Semarang, Central Java, Indonesia
}

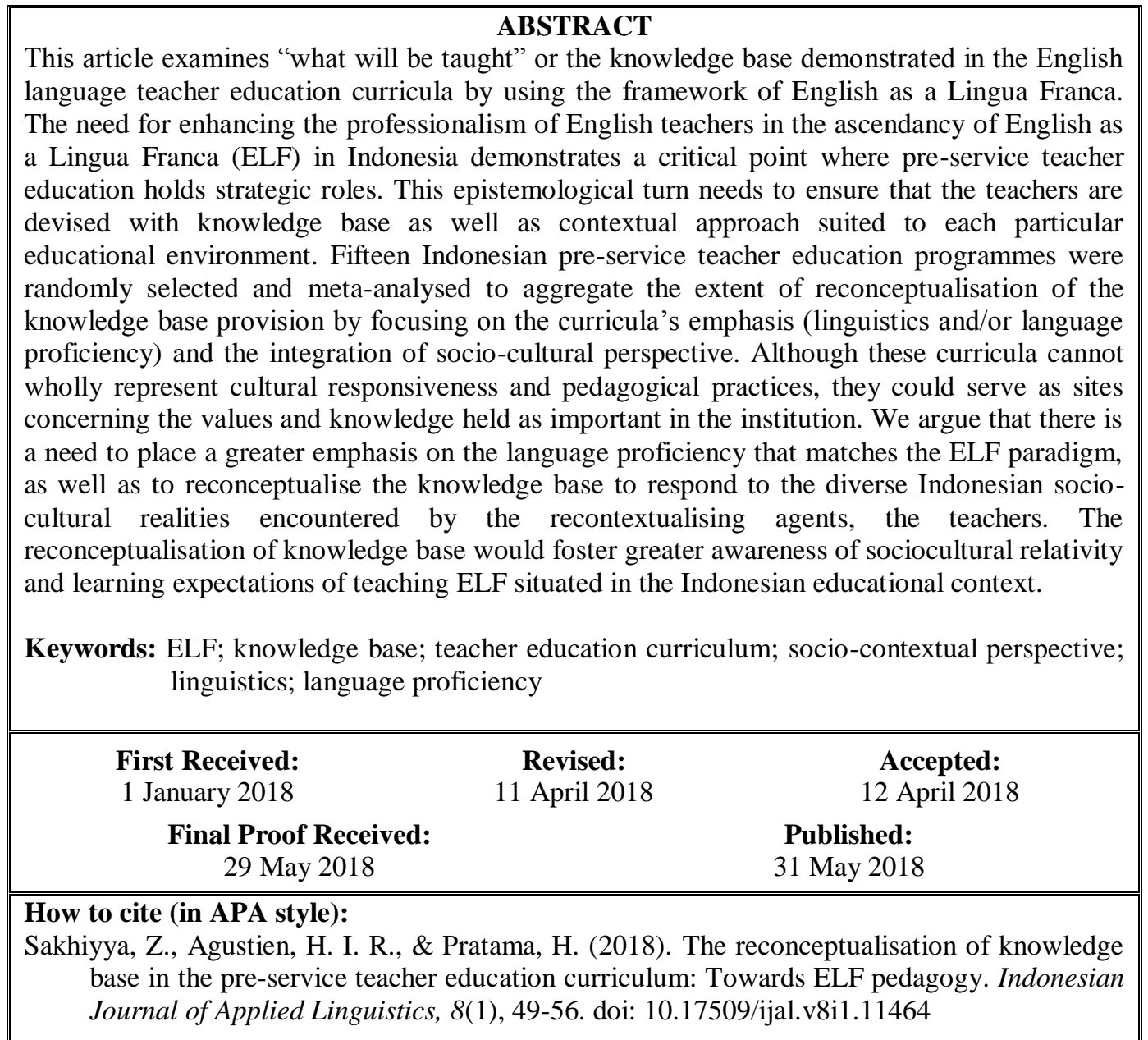

\section{INTRODUCTION}

The increasing trend of internationalisation and regionalisation in trade and politics, such as AsiaPacific Economic Cooperation and ASEAN Economic Community where Indonesia has actively involved, requires a lingua franca bridging the different linguacultures for none of whom English is the mother tongue. The last two decades have witnessed the unprecedented spread of English in the Asian region. Like in Europe (Seidlhofer, Breiteneder, \& Pitzl, 2006), English has been adopted as ASEAN's official language (Stroupe \& Kimura, 2015). Consequently, this rapid spread of
English in Asia repositions English in the region. As Kirkpatrick observes, "Asian multilinguals have taken ownership of English" (Kirkpatrick, 2016, p. 287), including Indonesia.

English as a Lingua Franca (ELF) is a conceptual term employed to refer to this growing linguistic phenomenon, by highlighting the relationship between the global use and spread of English and how it is taught and learned (Jenkins, 2006; Seidlhofer, 2004). Some studies suggest that most ELF interactions take place among non-native speakers of English (Seidlhofer, 2005) since only one in four English users is actually a

\footnotetext{
* Corresponding author:

Email: zulfasakhiyya@gmail.com
} 
native speaker of the language (Crystal, 2003). This is the momentum where English as a language has gained a truly intranational institutionalised role within those non-mother tongue countries, including Indonesia. Even without any historical roots in the past (Kirkpatrick, 2010), such as colonialism to establish the language in the country, English has become a lingua franca after Indonesia's national language (Murata \& Jenkins, 2009).

This new conceptual underpinning emphasises more on 'mutual intelligibility', rather than nativeness in the intranational communication, as well as 'appropriateness' rather than 'correctness' (Seidlhofer, 2001). The idea that mutual understanding in communication is more important than insisting to achieve a perfect native-like communication which is unlikely to happen (Seidlhofer, 2004). As a conceptual framework, ELF rejects the dominant monolithic view of English and advocates for a more equal position among different English varieties and users (Jenkins, 2006; Kirkpatrick, 2010; Seidlhofer, 2001, 2004, 2005).

According to Seidlhofer (2001), the problem with ELF as a conceptual framework is that although it offers rich and promising futures for English language teaching and learning, it only remains on the philosophical discussion. It rarely touches the empirical ground where the day to day negotiation of language control exists and the teaching and learning of English takes place. This study wishes to respond to this conceptual gap by looking at how this reorientation manifests in the field of English language teacher education.

Indonesia is a fertile ground for the growth of English as a lingua franca. Among Kachru's Outer Circle (1992), the country is the second largest market of English language education (Dardjowidjojo, 2000). The shift to ELF has major implications to the way English is conceptualised and taught in Indonesian teacher education institutions. This is an issue that deserves a further investigation more than ever in face of the shifting epistemology of English as well as the challenging times for the teaching profession (Flores, 2016). Previous researches have highlighted the 'failure' of English teaching in Indonesia by using a foreign language approach and hypothesised the English language teacher education as the source of the problems (Lengkanawati, 2005; Lie, 2007; Madya, 2002). More specifically, Lie (2007) has lamented that "very few high school graduates are able to communicate intelligibly in English" (p.1). English language teacher education institutions are the loci where these dynamic tension occurs (Grossman \& McDonald, 2008), not least because they need to keep up with these current realities by continuously maintaining their reflexivity over the knowledge base of what to teach in the programme. The responsibilities they hold are not only developing professional knowledge among practitioners, but also determining how professional language teachers are defined and reproduced. This shift consequently requires these institutions to ensure that teachers are devised with knowledge base as well as contextual approach suited to Indonesian socio-contextual environment (DogancayAktuna, 2005; Galloway \& Rose, 2017; Hu, 2005).

While the prominence of knowledge base within ELF framework is central to the success of English language teacher education, research on the knowledge base of the language teacher education programmes in Indonesia has been noticeably absent. This gap shows that the issue of knowledge base is an unexplored territory. It is thus urgent to examine whether the knowledge base provided by the English language teacher education institutions in Indonesia is sufficient and responsive to the contemporary realities within this shifting epistemology of English. The English language teacher education curriculum is selected as a key point of entry to look at what is offered by those institutions. Although curriculum documents cannot wholly represent cultural responsiveness and pedagogical practices, they could serve as 'windows' demonstrating the values and knowledge held as important in the institution.

The paper will firstly outline the knowledge base within ELF framework. Section two explains how curriculum provides a 'window' to see the knowledge base prescribed and described by the English language teacher education institutions. Section three introduces the empirical data obtained for this study. Section four analyses the curricula driven by a central question: how is the knowledge base reconceptualised in the curricula? Section five further discusses the findings and calls for the need of reconceptualisation of knowledge base to foster greater awareness of sociocultural relativity and learning expectations of teaching ELF situated in the Indonesian educational context.

\section{Reconceptualising the Knowledge Base of English Language Teacher Education within ELF Framework}

Knowledge base is the main conception of what student teachers need to know and are able to do to carry out the work as English teachers (Johnson, 2009). It is usually prescribed and described by teacher education institutions, although there are other stakeholders are involved in the process. For instance, in the Indonesian context, the Ministry of Education and Culture, the Ministry of Research and Technology and Higher Education, as well as industry sector usually play some considerable roles of defining what knowledge required by the institutions. It represents how English teachers are prepared by the institutions and how their professionalism is defined.

According to Johnson (2009), the knowledge base of English language teacher education reflects three broad fields: (1) the content of English language teacher education programmes: what student teachers need to know. This part is usually understood as the explicit knowledge about language or the linguistics component and the target language proficiency; (2) the pedagogies taught in the English language teacher education 
programmes: how student teachers need to teach, and (3) the institutional delivery through which both the content and pedagogies are learned: how the student teachers learn to teach. In a traditional foreign language teaching framework, the three fields above are controlled by the dominant view of English where standards and goals are fairly stable and certain (Seidlhofer, 2004). The view and control which rests with speakers for whom English is the first language.

Reconceptualising the knowledge base of English language teacher education within ELF Framework means that the knowledge base is approached from ELF perspectives rather than from a predominant view of monolithic English (House, 1999; Jenkins, 2006; Murata \& Jenkins, 2009). Through the knowledge base, teachers of English are equipped to enable them to understand the implications of the shifting position of English. This does not mean that adopting an ELF perspective does not require any norms and standards, rather they are mutable concepts and understandings of the varieties of English which need to be critically introduced (Sewell, 2013). In ASEAN, for example, there are Singaporean English (or Singlish) and Pilipino English. English in Singapore and Philippine is a second language due to mainly British colonial history in the past (Kirkpatrick, 2010). Although English cannot be regarded as a second language in Indonesia, the language has increasingly filled up the ecological space of modern society (Kirkpatrick, 2010; Lamb \& Coleman, 2008). There should be Indonesian English too. By the same token, Kirkpatrick (2010) proposes the idea that English will be a truly global language only when "we can move from talking about 'post-colonial' varieties to a post-Anglophone stage, where the major international role of English is as a lingua franca and where native speakers of English are not necessarily present" (p. 74). To build this critical awareness, the new ELF paradigm requires teachers to become recontextualising agents. Rather than just being trained in an assumed teaching context, teachers need a more comprehensive knowledge and training that enable them to recontextualise their English teaching suited to particular educational environment. This is done through reconceptualising the knowledge base for the recontextualising agents.

McKay (2004) argues that the reconceptualisation of knowledge base starts with critically questioning and challenging the dominant view of English as prescribed by native-speaker models. It then follows with recognising the varieties of English resulting from the unprecedented global spread of the language. The intercultural nature of the use of English within multilingual communities also need to be taken into account. McKay's principles are useful in reconceptualising the knowledge base within ELF framework. It emphasises the values of sensitivity, reflexivity, and respect that should be held important in the knowledge base. Seidlhofer (2004) further articulates McKay's proposal that the three fields of knowledge base, i.e., content, pedagogy, and situated learning, should reflect the "sensitivity in the choice of cultural content in materials, reflexivity in pedagogical procedures, and respect for the local culture of learning" (p. 226).

In the Indonesian context, we argue that ELF framework fits with the multilingual and multicultural conditions of Indonesia. The long history of Indonesian national language as a lingua franca unifying people of different ethnicities and languages has proven that cultural awareness is inseparable from language teaching. This includes English teaching and learning. This means that the knowledge base designed by the language teacher education should ideally reflect and represent the multilingual and multicultural conditions of Indonesia. However, this issue has been understudied. It is therefore the impetus of this study to re-dress the imbalance in the literature and contribute to the discussion of ELF knowledge base provision in the Indonesian context.

\section{Curriculum as a 'Window' to Knowledge Base}

English language teacher education curriculum is selected a key point of entry to look at the knowledge base within the shifting epistemology of English position, teaching and learning. Although curriculum documents cannot wholly represent cultural responsiveness and pedagogical practices, they could serve as a 'window' demonstrating the values and knowledge held as important in the institution. Curriculum reflects not only the linguistic and pedagogical elements, but also the political and ideological processes happening behind its development (Flores, 2016). Like a window, curriculum is relatively smaller than the house itself, but it provides insights for observing a larger vision of the nature and position of English, and how English language teacher education institutions set the standards of what counts as professional English teachers they produce.

In addition to serving as 'window', curriculum is the site where the most radical changes happen in English teaching. The shifting epistemology of English from nativeness to intelligibility finds its expressions in the curricula and materials. This study focuses on the former where the changes take place and can be analysed.

The need to reconceptualise English language teacher education curriculum aligned with ELF framework has been reiterated in the literature (see Kirkpatrick, 2010; Seidlhofer, 2005). Within this view, curriculum is seen as the knowledge base which provides basic understandings of English as a lingua franca, the lingua franca approach, and ELF pedagogy. Kirkpatrick (2010) suggests that ELF curriculum needs to include regional and local cultures relevant for lingua franca users in the ASEAN region, thus enabling students to be critically reflexive of their own cultural values and interests in English. Nevertheless, publication concerning English language teacher education curricula analysis by employing ELF framework is extremely scarce. This is an issue that 
needs to be explored empirically and descriptively as a basis to formulate a curriculum for the teaching of ELF.

Previous studies on the curriculum of English language teacher education in Indonesia, however, were more concerned with standardising curricular components (see Bismoko, 2003; Luciana, 2004; Madya, 2002; Widodo, 2016). While those studies have been helpful in identifying the problems with curriculum and providing alternative solutions, they suggest that there is one standard of English to deal with, that is English as a native language (Seidlhofer, 2001) and it is where the standards or competence derived from. Not only that such a perspective maintains the monolithic view of English (which is against the ELF spirit), it does not respond to the current challenges and realities of English learning in Indonesia. In addition, there has not been any study examining English language teacher education curricula at various pre-service teacher education programmes in Indonesia in terms of their provision of knowledge base and contextual approach for teaching ELF. This absence of area of inquiry shows problems of emphasis in what are considered as central understandings in this field.

This study is a response to the absence of such a research. The study utilises English language teacher education curricula analysis focusing on "what will be taught" or knowledge base (Graves, 2009) within the socio-contextual perspective (Graves, 2008). For the purpose of the study, pre-service English language teacher education curriculum documents were gathered from fifteen higher education institutions across the Indonesian archipelago including cities such as Jakarta, Yogyakarta, Surabaya, Padang, Semarang, Bali, and Aceh. These curricula were meta-analysed in terms of their knowledge base provision by using ELF framework to aggregate the results on our topic of interest (Erford, Savin-Murphy, \& Butler, 2010) - the reconceptualisation of knowledge base.

The fifteen curriculum documents were randomly gathered to provide an overview of the extent to which the reconceptualisation of the knowledge base of English language teacher education occurs in Indonesia. The fifteen curriculum documents were meta-analysed by focusing on the curriculum form, structure and content. Curriculum form deals with the knowledge and values considered important in the curriculum. Curriculum structure refers to the outline of the content. For the content, we looked at the curricula's emphasis (linguistics and/or language proficiency) and the integration of socio-cultural context.

\footnotetext{
The Degree of Reconceptualisation of the Knowledge Base

How is this knowledge base reconceptualised? We would argue that although the reconceptualisation of knowledge base occurs, it is not enough to respond to the urgency of ELF. The reconceptualisation is evident from curriculum content with the availability of cultural related courses (such as Cross-Cultural Understanding and Introduction to Cultural Studies). Nevertheless,
}

curriculum forms and structure still reflect the monolithic English view. The main point of reference and standards for most of the curricula remain the codified standards or competences, grammars, dictionaries and textbooks of that of native speaker norms. This reflects Seidlhofer's concern (2001) on the conceptual gap of ELF: "Despite momentous developments in the sociopolitics of the teaching of English worldwide, targets have generally remained tied to native speaker norms" (p. 133).

The key features of the fifteen curricula related to the knowledge base and ELF framework are presented in the findings below. Due to space limitations, a detailed analysis of the content of the curricula is beyond the scope of this paper.

\section{Competence-based Curriculum}

The knowledge and values deemed as important by the institutions are conceptualised into 'competence' matrix. Our findings reveal that all of the fifteen curricula under review are based on 'competence'. The current orientation of most Indonesian higher education curricula to competence is regulated by the Indonesian National Qualification Framework and the National Standard of Indonesian Higher Education (Agustien, 2017). This includes English language teacher education. The Ministry of Research and Technology and Higher Education considers competence-based curriculum as measurable, efficient and responsive to contemporary challenges because it describes and prescribes the key demonstrable learning achievements and outcomes (Ministry of Research and Technology and Higher Education, 2015). The formulated outcomes need to meet the expectations of the professional communities in which the graduates will be a part of.

From a bird eye view, this is actually the trend of 'performativity' that has dominated the education system worldwide since 1970s (Lyotard, 1984). The idea where accountability and quality is defined by performance, and competence-based curriculum is one manifestation of this (Flores, 2016). It came to Indonesia around early 2000s for secondary and high school curriculum(Agustien, 2017; Lie, 2007; Madya, 2008; Widodo, 2016). The curriculum usually derives its analysis of a prospective or actual role in the society (in this case, English teacher) and attempts to qualify and certify student progress on the bases of demonstrated performance in some or all of the aspects of that assumed role.

The standards and competences espoused by the curricula are around the following area:

- Communicative competence - graduates are able to communicate in English actively, confidently and politely supported by their mastery of the listening, speaking, reading and writing in English using the elements of vocabulary, grammar, pragmatics and culture appropriately;

- Pedagogic competence - graduates are able to carry out English lessons using active, 
innovative, creative and effective methods, techniques, strategies and approaches in democratic ways by using media and information technology that incorporate the environmental, knowledge and cultural awareness;

Technological and cultural competence graduates are able to carry out English trainings using innovative approaches and the latest technology that incorporate cultural awareness and firmly uphold the values of nationalism.

In general, the curricula have included cultural competence as one of its key competences. This demonstrates the effort to recognise culture as one key component in learning. As written in the curricula structure, this cultural competence is translated into cultural related courses. This is further discussed in the next sub-section.

\section{Cultural related Courses as Reflexivity}

The reconceptualisation of the knowledge base can be seen in the curriculum content. This is evident by the availability of cultural related courses which aims to serve as a reflexive tool to one's own culture (nonmother tongue culture) and to understand more that of mother tongue culture. The courses are 'Cross-Cutural Understanding' and 'Introduction to Cultural Studies'.

The 'Cross Cultural Understanding' course exists in all fifteen curricula. It studies "cross cultures by analysing certain cultures and their background which are manifested in the society, and then recognising, identifying, balancing other cultures with one's cultural system" (University B curriculum, 2012, p. 24). University A describes this course in a more vivid way. "This course explores numerous questions and analyses cultural similarities and differences with regards to Eastern [such as Indonesian] and Western [such as American and British] cultures. Recognizing that each society has its own beliefs, attitudes, customs, behaviours, and social structures, students are able to understand that people have a sense of identity, standards by which to live, and goals to strive for; that the term "culture" has many different meanings, referring to the patterns of belief and behaviour common to a particular group of people [such as the reasons why English people think and behave the ways they do]." (University A, 2011, p. 38).

The other cultural related course, 'Introduction of Cultural Studies' course, only exists in one curriculum. It offers "concepts and theories as well as their implementation to understand and appreciate the cultural and social diversity" (University B curriculum, 2012, p. 19). This course is more general than the former one as it studies culture in as an abstract concept.

Cultural related courses such as 'Cross Cultural Understanding' and 'Introduction to Cultural Studies' courses are important to introduce cultural diversity and differences, especially the dichotomy between the East and West. For prospective English language teachers, such courses are helpful in answering the questions "why English people think and behave the ways they do" (University A, 2011, p. 38), what cultural conditions that generate certain idiomatic expressions, and how the language is used and practiced within particular cultural context (native setting). However, we would argue that it is not sufficient to build awareness on the 'World Englishes'. More worryingly, it maintains the monolingual bias and stereotype of English as a monolithic entity (Galloway \& Rose, 2017), thus widening the presumed existing gap between the East and West.

\section{Curriculum Structure}

Curriculum structure outlining the content of the curriculum varies across curriculum documents, but their contents are more or less similar. Knowledge base is ordered according to their level of complexity and challenges. Some curricula prefer structuring the knowledge base by this complexity level, some others use numbering. As an illustration, the grammar courses are highlighted here. In five universities accredited with " $A$ " level, the curriculum documents use numbering to label the grammar courses. They are labelled "Structure 1", "Structure 2", "Structure 3", and "Structure 4". These labels can mean anything to the curriculum users within a university, let alone across universities in the country. No one can confidently say that these courses adopt a traditional perspective. Nor can one be confident in saying that these labels are functional or sociolinguistic in nature in which grammar is seen as a resource in the creation of intelligible spoken and written texts. The same case also applies to Reading, Speaking, Listening and Writing courses. For these language proficiency courses, it is also difficult to analyse the structure of the Listening courses because of the label "Listening 1", "Listening 2", "Listening 3", and "Listening 4", let alone commenting on the degree of reconceptualisation of knowledge base.

It is worth re-stating here that adopting the ELF framework in the curricula would mean that there is "sensitivity in the choice of cultural content in materials, reflexivity in pedagogical procedures, and respect for the local culture of learning" (Seidlhofer, 2004, p. 226). For instance, Listening, Phonology and Pronunciation Practice courses need to include a wide array of pronunciation varieties of Asian Englishes as well as the recognition of the influence of any distinctive regional Indonesian that is close to the student teachers. English language teacher education in Java island, for example, needs to recognise and expose their students with the critical awareness of the influence of Sundanese (West Java), Maduranese (Madura island), Surabaya (East Java), let alone the wide varieties of Central Java accents such as the North Seashore Banyumasan area (Uhlenbeck, 1964), Solo, and Yogyakarta. Each of these accents has certain degree of influence on English pronunciation. In the book on the phonology of English as an international 
language, Jenkins (2006) argues that instead of assessing learners' approximation to a native speaker accent, more emphasis should be taken of "the ways in which [student teachers] adapt their pronunciation to facilitate one another's understanding, and the extent to which they successfully achieve mutually intelligible pronunciation" (p. 213).

If the main point of reference for most of the curricula is the codified grammars, dictionaries, textbooks and pronunciation of that of native speaker norms, it then reflects the predominant English view and native speaker norms. This reference point could only be observed through the syllabus and learning materials which is beyond the scope of this paper. However, as far as the discussion of curricula structure concerned, what needs to be highlighted regarding the reconceptualisation of knowledge base is the allocation of the types of knowledge presented in the curriculum structure which begs the question: which knowledge needs more emphasis? This is discussed in the next subsection.

\section{Knowledge about language versus language proficiency}

The majority of the curricula offer courses concentrating on theories of language teaching and teaching skills. To achieve the goals, however, they place a heavy emphasis on linguistics or knowledge about language than language proficiency. As an illustration of an A accredited programme, the curriculum outlines 20-24 courses of language skills, 32 courses of linguistics, 54 of pedagogical courses, 10 courses of community involvement, and 8 courses of personality development. Such a course ratio reflects the other 14 curricula under review which places more emphasis on knowledge about the target language than language proficiency.

The emphasis on linguistics contributes to a general understanding about English, but does not necessarily improve the student teachers' language proficiency. This imbalance knowledge base provision answers the deep-seated problems of the low proficiency level of the Indonesian English language teachers consistently highlighted in the previous studies (see Dardjowidjojo, 2000; Hamied, 2011; Jazadi, 2000). The implication of this finding is that English language teacher education needs to equip the student teachers with both pedagogical knowledge and adequate English proficiency in order to enable them to improve their students' English proficiency level when they embark on teaching duties.

\section{CONCLUSION, LIMITATION RECOMMENDATION}

There are two main findings presented in this article. Firstly, the assessment of reconceptualisation of knowledge base within ELF framework has been done through the aspects of curriculum form (competencebased curriculum), content (cultural related courses), structure (the ordering of the knowledge base), and emphasis (linguistics or language proficiency). They demonstrate that the reconceptualisation of knowledge base occurs but not sufficient enough to move the tide of ELF framework. This lack of emphasis on and integration of socio-cultural context with the knowledge base demonstrates that such provision is culturally irresponsive and potentially leads to a counterproductive teacher education which will reproduce cultural irresponsiveness (Johnson, 2006, 2009). The central issue here is not so much a contestation between the content or ELF knowledge base with the socio-cultural context, but the integration of socio-cultural context with the knowledge base.

Secondly, we argue that there is a need to place a greater emphasis on the language proficiency as well as to reconceptualise the knowledge base to respond to the diverse Indonesian socio-cultural realities encountered by the recontextualising agents. The reconceptualisation of knowledge base would foster greater awareness of sociocultural relativity and learning expectations of teaching ELF situated in the Indonesian educational context.

Considering the limitation of this article, there is a need to examine the syllabus and learning materials (such as textbooks, dictionaries, listening materials, etc) used in English language teacher education programmes to carefully see the reconceptualisation of sociocultural contexts over English.

\section{REFERENCES}

Agustien, H. (2017). A Philosophical Mismatch between English Education and High School Curricula. In ASIA TEFL 2017. Yogyakarta: ASIA TEFL.

Bismoko, J. (2003). Does our English teacher education need re-designing? TEFLIN Journal, 14(1), 58-69.

Crystal, D. (2003). English as a Global Language (second edi). Cambridge: Cambridge University Press.

Dardjowidjojo, S. (2000). English teaching in Indonesia. EA Journal, 18(1), 22-30.

Dogancay-Aktuna, S. (2005). Intercultural communication in English language teacher education. ELT Journal, 59(2), 99-107. https://doi.org/10.1093/eltj/cci023

Erford, B. T., Savin-Murphy, J. A., \& Butler, C. (2010). Conducting a meta-analysis of counseling outcome research: Twelve steps and practical procedures. Counseling Outcome Research and Evaluation, 1, 19-43.

Flores, M. A. (2016). Teacher Education Curriculum. In International Handbook of Teacher Education (Vol. 2, pp. 187-230). https://doi.org/10.1007/978981-10-0366-0

Galloway, N., \& Rose, H. (2017). Incorporating Global Englishes into the ELT classroom. ELT Journal, 1-12. https://doi.org/10.1093/elt/ccx010

Graves, K. (2008). The language curriculum: A social 
contextual perspective. Language Teaching, 41(2), 147-181. https://doi.org/10.1017/S0261444807004867

Graves, K. (2009). The curriculum of second language teacher education. In A. Burns \& J. C. Richards (Eds.), The Cambridge guide to second language teacher education (pp. 115-124). New York: Cambridge University Press.

Grossman, P., \& McDonald, M. (2008). Back to the future: Directions for research in teaching and teacher education. American Educational Research Journal, 45(1), 184-205.

Hamied, F. A. (2011). English as a lingua franca: An Indonesian perspective . Keynote speech Hong Kong, 26-28 May. In The fourth international conference of English as a lingua franca, Hong Kong, 26-28 May 2011. Hongkong.

House, J. (1999). Misunderstanding in intercultural communication: interactions in English as a lingua franca and the myth of mutual intelligibility. In C. Gnutzmann (Ed.), Teaching and learning English as a global language (pp. 73-89).

$\mathrm{Hu}, \mathrm{G}$. (2005). Contextual influences on instructional practices: A Chinese case for an ecological approach to ELT. TESOL Quarterly, 39(4), 635660. https://doi.org/10.2307/3588525

Jazadi, I. (2000). Constraints and resources for applying communicative approaches in Indonesia. $E A$ Journal, 18(1), 31-40.

Jenkins, J. (2006). Current perspectives on teaching World Englishes and English as a Lingua Franca. TESOL Quarterly, 40(1), 157-181. https://doi.org/10.2307/40264515

Johnson, K. E. (2006). The Sociocultural Turn and Its Challenges for Second Language Teacher Education. Journal of Special Education Technology, 40(1), 235-257. https://doi.org/10.1016/B978-0-08-0970868.92085-3

Johnson, K. E. (2009). Second Language Teacher Education: A sociocultural perspective. New York: Routledge.

Kachru, B. (1992). The other tongue (second edi). Urbana: University of Illinois Press.

Kirkpatrick, A. (2016). English as a lingua franca and its educational impact in Asia.

In G. Leitner, A. Hashim, \& H.-

G.Wolf (Eds.), Communicating with Asia: The future of English as a global language (pp. 282295). Cambridge: Cambridge University Press. doi:10.1017/CBO9781107477186.019

Kirkpatrick, A. (2010). English as a Lingua Franca in ASEAN: a Multilingual Model. Project MUSE. Hong Kong: Hong Kong University Press. https://doi.org/10.1080/01434632.2012.661439

Lamb, M., \& Coleman, H. (2008). Literacy in English and the transformation of self and society in postSoeharto Indonesia. International Journal of Bilingual Education and Bilingualism, 11(2), 189205. https://doi.org/10.2167/beb493.0
Lengkanawati, N. S. (2005). EFL teachers' competence in the context of English curriculum 2004 : Implications for EFL teacher education. TEFLIN Journal, 16(1), 79-92.

Lie, A. (2007). Education policy and EFL curriculum in Indonesia: Between the commitment to competence and the quest for higher test scores. TEFLIN Journal, 18(1), 1-14. https://doi.org/10.15639/TEFLINJOURNAL.V18I $1 / 1-15$

Luciana, L. (2004). Developing standards for language teacher education programs in Indonesia: Professionalizing or losing in complexity? TEFLIN Journal, 15(1), 27-41.

Lyotard, J.-F. (1984). The Postmodern Condition: A Report on Knowledge. University of Minnesota Press.

Madya, S. (2002). Developing standards for EFL in Indonesia as part of the EFL teaching reform. TEFLIN Journal, 13(2), 142-151.

Madya, S. (2008). Curriculum innovations in Indonesia and the strategies to implement them. In Y. H. Choi \& B. Spolsky (Eds.), ELT Curriculum Innovation and Implementation in Asia (pp. 1-38). ASIA TEFL.

McKay, S. L. (2004). EIL curriculum development. In English in the world: Global rules, global roles. Bangkok: IELE Press at Assumption University.

Murata, K., \& Jenkins, J. (2009). Global englishes in asian contexts: Current and future debates. New York: Palgrave Macmillan.

Seidlhofer, B. (2001). Closing a conceptual gap : the case for a description of English as a lingua franca. International Journal of Applied Linguistics, 11(2), 133-158. https://doi.org/10.1111/14734192.00011

Seidlhofer, B. (2004). Research Perspectives on Teaching English as a Lingua Franca. Annual Review of Applied Linguistics, 24, 209-240. https://doi.org/10.1017/S0267190504000145

Seidlhofer, B. (2005). English as a Lingua Franca. ELT Journal, 59(4), 339-341. https://doi.org/10.1093/elt/cci064

Seidlhofer, B., Breiteneder, A., \& Pitzl, M.-L. (2006). Applied Linguistics. Annual Review of Applied Linguistics, 26(3), 3-34.

Sewell, A. (2013). English as a Lingua Franca: Ontology and ideology. ELT Journal, 67(1), 3-10. https://doi.org/10.1093/elt/ccs061

Stroupe, R., \& Kimura, K. (2015). Opportunities and challenges across ASEAN: Looking ahead to the ASEAN Economic Community. In R. Stroupe \& K. Kimura (Eds.), ASEAN integration and the role of English language teaching (pp. 1-12). Pnom Penh: IELTS.

Uhlenbeck, E. M. (1964). A critical survey of studies on the languages of Java and Madura. The Hague: Koninklijk Instituut voor Taal-, Landen Volkenkunde

Widodo, H. P. (2016). Language policy in practice: 
Indonesian Journal of Applied Linguistics, 8(1), May 2018

Reframing the english language curriculum in the Indonesian secondary education sector. In R.

Kirkpatrick (Ed.), English language education policy in Asia (Vol. 11, pp. 127-151). Switzerland:
Springer International.

https://doi.org/10.1080/13488678.1998.10800995 